\title{
Does Gold Shine in the Portfolio of a Kuwaiti Investor?
}

\author{
Yaser AlKulaib (Corresponding author) \\ College of Business, Kuwait University \\ PO Box 5486 Safat 13055, Kuwait \\ Tel: 965-24-988-480 E-mail: yalkulaib@cba.edu.kw \\ Fahad Almudhaf \\ College of Business, Kuwait University \\ PO Box 5486 Safat 13055, Kuwait \\ Tel: 965-24-988-480Ｅ-mail: fmudhaf@cba.edu.kw
}

Received: July 29, 2011

doi:10.5539/ijef.v4n1p160
Accepted: August 23, 2011

Published: January 1, 2012

URL: http://dx.doi.org/10.5539/ijef.v4n1p160

\begin{abstract}
Gold is known to be a stable investment in times of political and economic uncertainty. Our article is the first to examine the diversification benefits of including gold in the portfolio of a Kuwaiti investor. Our empirical results for the period Jan 2000 to May 2011 show that Kuwaiti investors will gain benefits by adding gold to their portfolios. The results of the Johansen cointegration tests show that gold and KSE index are not related in the long run. In addition, we find that gold has a weak and insignificant correlation with KSE index.
\end{abstract}

Keywords: Gold, Portfolio, Diversification, Kuwait stock, Investment

\section{Introduction}

Nowadays, individuals read many headlines regarding gold prices as hitting high records because of the Euro and US debt crises of July 2011. Such news and uptrend in the price of gold attracts more attention to its value as an investment. It grabbed the attention of individuals who would like to weight the benefits of including gold to their equity portfolio. O'Bryne (2007) lists several fundamental reasons for owning gold. US trade and current account deficits, falling property values, geopolitical instability, weak dollar, increase demand for safe haven assets, hedging against macroeconomic risk are among the reasons included by O'Bryne.

After the recent financial crises, investors became more risk averse seeking higher returns for the level of risk. Investors look to lower the risk they take and maintain the portfolio return they have. Global investor becomes interested in gold as an investment security that can diversify investor portfolio. As equity markets become intergraded, investors benefit by adding to their portfolio assets that have low correlation with their investment, and as research suggest that gold have low correlation with equity. So, investors will benefit by adding gold to their investment portfolio. The impact of the financial crisis which was originated in USA and Euro Zone, has hit the rest of the world. Gulf Cooperation Council (GCC) was one of the regions that were affected with that crisis.

In our paper we will focus in Kuwait as one the GCC state, and how Kuwaiti investors will benefit from adding gold as investment financial instrument to their portfolio. Diversification by itself is not an easy process since if your added securities to a portfolio it may end up with securities react the same way to market risk. Financial literature suggests the benefit for diversification of international securities and other investment securities to institutional and individual investor. Gold may offer diversification benefits to investor portfolio, as gold return is likely to differ from that of common stocks because of low correlation. This paper examines the benefits of gold in investor portfolio. We will examine the correlations between gold and market return and the effect of gold to portfolio performance.

Our analysis incorporates the recent bull-run in gold prices as well as the extended bear-period from the financial crisis in 2008 in stock market. Our study extends the literature by presenting evidence using data from Kuwait, which is a frontier market that has not been previously covered in terms of diversifying portfolios using gold. Results of our study should be beneficial to individual investors, institutional investors and portfolio managers interested in diversification. 
The paper will be divided into four coming parts. First, we will discuss previous studies in was done in that topic. Second, we will explain the data set and methodology will be followed. Third, we undertook the analysis from empirical results and discuss it from Kuwaiti investors' perspective. Finally, it will be the paper conclusion.

\section{Literature Review}

There is considerable body of empirical evidence documenting the benefits of including gold to investor portfolio. The literature on the role of gold in financial markets covered; diversification investments in financial portfolios, and gold as potential hedging variable. Many papers studied the role of the gold as investment financial assets. Gold prices as precious metal can respond in short-term and long-term factors. Some of the factors are central banks holdings of gold as primary form of reserve asset and supply and demand of investors to gold. The market for gold is exceptionally liquid, so private and institutional investors can trade gold as financial investment. The demand from private investment comes from physical holding of bars, investment in financial gold securities or gold exchange traded fund (ETF).

Investors can add gold to their portfolio to reduce the portfolio's risk as has been supported by empirical studies. Jaffe (1989) and Chua et al. (1990) show that investors can invest in gold to diversify their investment portfolio. Jaffe (1989) examine correlations between gold and other assets, and the effect of gold on the performance of a representative portfolio. The author shows low correlations between gold and other asset classes. Also gold has no relationship with common stocks, long-term government and corporate bonds, and real estate returns. As a result, after allocating 5 percent of portfolio to gold, return increased while standard deviations decreased. Furthermore, he finds that gold is not a good inflation hedge.

More recent studies highlight the continued interest in gold as an investment. Hillier et al. (2006) find that gold and other precious metals have potential diversification benefits and hedging capability, and enhance the performance of equity portfolios. Hillier, Draper, and Faff (2006) examine where precious metals provide valuable diversifying qualities beyond those achievable in a portfolio devoted solely to financial assets. Hillier et al. finds that precious metals have some hedging capability even during periods of abnormal stock market volatility. Hillier et al. (2006) and Jaffe (1989) finds that financial portfolios that contain gold perform significantly better than standard equity portfolios over the past 25 years when adding as low as 9.5 percent. Hillier et al. notes that precious metals (gold, platinum, and silver) provided diversifying benefits in volatile markets when held in a portfolio of U.S. or global stocks, which means that even investor in GCC will benefit if they held global stocks. In addition, they find that during periods of high market risk, precious metals were more negatively correlated with stock market returns. Consequently, all precious metals have hedging capability during periods of abnormally high stock market volatility. So, will gold provide the same benefits for GCC or Kuwaiti investors? That's what we will try to answer in our paper.

Ratner and Klein (2008) investigate the value of gold as stand-alone investment, and assess the benefit of including the metal as port of a global investment portfolio. It is shown that gold as stand-alone investment is relatively poor investment compared with the U.S. stock market over the long-term. Furthermore, it is shown historically that gold has generally low or negative correlations with U.S. equities. Conover, et al. (2009) finds that portfolio performance improves substantially when a prominent portion of the portfolio is re-allocated to the equities of precious metals firm, for U.S. equity investor. In addition, the authors find the investment benefits are considerably larger if the exposure to precious metals is obtained indirectly via an investment in the equities of precious metals firm, rather than directly by purchasing the precious metal as a commodity.

In recent study by Baur and Lucey (2010) tested whether gold is safe haven asset, not hedge or diversifier asset. According to authors, they are not aware of any study actually testing whether gold is a safe haven asset. They based their test on a regression model in which gold returns are regressed on stock and bond returns and two interaction terms that test whether gold indeed serves as a safe haven if stock or bond markets fall or exhibit extreme negative returns. The empirical analysis was done on United States, United Kingdom, and Germany financial markets.

The empirical analysis by Baur and Lucey (2010), shows that gold is a safe haven for stocks in U.S., U.K., and Germany as earlier studies shows, but not a safe haven to bonds. After they done a subsample analysis into bull and bear market regime, the interesting finding was that gold is not a safe haven for stocks at all times, but only after extreme negative stock market shocks, by finding gold estimates highly significant in bear market in all three markets analyzed. The finding limitation for gold as a safe haven, that gold is a safe haven for only 15 trading days.

Our paper extends the literature along several important dimensions. First, it is an extension to the literature of gold to Kuwaiti investor as a frontier market which has not been previously tested. Second, we test the benefits of adding $10 \%, 20 \%$, or $30 \%$ of gold to investor portfolio. Finally, we examine the consistency of benefits over current time period which covers the recent financial crises. 


\section{Data}

Our analysis incorporates the recent bull-run in gold prices as well as the extended bear-period from the financial crisis in 2008 in stock market. We use monthly closing prices of Kuwait stock exchange (KSE) price index and MSCI world equity index from Reuters Xtra 3000 database. Our monthly gold data prices are from World Gold Council website. Also, we use closing price of monthly Dow Jones Global Real Estate Securities Index. In addition, we use monthly Global Kuwaiti Dinar (KD) money market fund. Our sample period extends from January 2000 to May 2011. We calculate the logarithmic returns for each index. We converted gold price to Kuwaiti Dinar (KD) using foreign exchange data obtained from Reuters. Table 1 shows the basic descriptive statistics of our data. The coefficient of variation (CV) shows risk per unit of return. Over the 10-year period, the coefficient of variation indicates that gold dominated the other assets on a stand-alone basis.

Insert Table 1 Here

Figure 1 shows the return pattern for gold denominated in Kuwaiti Dinar (KD) versus the return of Kuwait stock exchange price index. We note that the graph indicates weak relation between returns. We should be cautious that one cannot depend on such a simple graph to reach a conclusion on the diversification benefits of the inclusion of gold in a portfolio.

\section{Insert Figure 1 Here}

\section{Method and Results}

In order to have better diversification benefits an investor prefers to add assets with low correlation with the existing assets in the portfolio. Therefore, we begin our analysis with a correlation matrix of the returns for all of the assets during our sample period. Table 2 presents the correlation results. We note that there is a very low and negative correlation between gold and Kuwait stock return. The low correlation can be viewed as a good indicator from an investor who is looking to diversify his/her portfolio.

Insert Table 2 Here

We then regress the return on gold against the return of KSE index as shown in equation 1.

$$
R_{G t}=c+b\left(x_{t}\right)+\varepsilon
$$

Where the dependent variable is the monthly logarithmic rate of return on Gold, the independent variable is the monthly logarithmic return on Kuwait Stock Price Index, $\mathrm{c}$ is the intercept, $\mathrm{b}$ is the beta or systematic risk and $\varepsilon$ is the random error term. Newey-West heteroskedasticity and autocorrelation adjusted standard errors are used to estimate the t-statistics. Table 3 shows that the coefficient is statistically insignificant which supports the fact that gold is a good diversifier. This is true during the whole sample (Jan2000-May2001) and the subsample that represent bear market (Jan2007-May2011). It has been shown in the literature that co-movements between equities and asset classes increase during turmoil periods when investors are in real need of diversification. However, Gold continues to have insignificant relation with the stock market even during turmoil periods such as the financial crises of 2007. This is consistent with the finding that during bad market periods, gold is advocated as a safe haven.

\section{Insert Table 3 Here}

In order to identify if there is a long-term relation between gold and stock, we use Johansen (1991, 1995) cointegration test as shown in the vector autoregressive (VAR) equation (2).

$$
\Delta y_{t}=\prod \quad y_{t-1}+\sum_{i=1}^{p-1} \quad \Gamma_{i} \Delta y_{t-i}+B x_{t}+\varepsilon_{t}
$$

Where $\mathrm{x}$ is the vector of deterministic variable, $\varepsilon$ is vector of the innovation, and $\mathrm{y}$ is vector of non-stationary variables. $\prod=\sum_{i=1}^{p} A i-I$ and $\Gamma_{i}=-\sum_{j=i+1}^{p} A j$.

$r$ is the cointegtaing rank which is the number of cointegrating relationships. Johansen method estimates $\prod$ matrix from VAR.

Unit root tests (Dickey and Fuller (1979), Phillips and Perron (1988)) are used to test the stationarity of the gold and stock price variables. We fail to reject the null hypothesis that the variables have a unit root for both KSE and gold. Unit root results in Table 4 shows that the level of the gold price and the KSE index are non-stationary. The variables are cointegrated if the linear combination is stationary which supports the fact that there is a long-run relationship between the two variables. Trace test results in Table 5 shows that gold is not cointegrated with KSE price index. Max-eigenvalue test also indicates no cointegration at the $5 \%$ level. This is good news for an investor who is willing to add gold into his portfolio. Cointegration results show that there is no significant long-term relationship between gold and Kuwaiti stock index.

Insert Table 4 Here 
Insert Table 5 Here

Figure 2 presents the returns of a $100 \%$ investment in Kuwait stocks versus a portfolio with $20 \%$ allocated to gold and $80 \%$ to equities. Panel (A) which shows the whole sample period shows that $1 \mathrm{KD}$ invested in equities since Jan 2000 would have grown to $3.43 \mathrm{KD}$ in May 2011. It also shows that during the same period $1 \mathrm{KD}$ invested in the diversified portfolio of gold and equity has grown to $3.62 \mathrm{KD}$ up to $3.93 \mathrm{KD}$ depending on the percentage of Gold invested in the portfolio. Figure 2 shows the outcome of $10 \%$ invested in Gold as compared to $30 \%$ invested in Gold. Panel (B) restricts the sample to the subperiod (bear market) from Jan 2007 to May 2011. It shows that an investor with more Gold in the portfolio minimizes his loss during this period. All in All, Gold shows to be good exposure to the portfolio of a Kuwaiti investor.

Insert Figure 2 Here

Based on Markowitz theory, we use mean-variance portfolio optimization techniques with no short sales constraint. Our results indicate that gold maintains an important presence in the portfolio which minimizes the variance as well as the portfolio which maximizes the Sharpe ratio. Overall, it seems that Kuwaiti investors can use gold to diversify their portfolios. Our findings are consistent with the previous literature in developed markets as supported in early work on U.S. and Euro financial markets.

\section{Conclusion}

Unlike previous work focusing on the benefits of diversifying with gold from the US investor perspective, our paper examines whether gold is a good diversifier for the Kuwaiti investor. The results of the Johansen cointegration tests show that gold and KSE index are not related in the long run. In addition, we find that gold has a weak and insignificant correlation with KSE index. As a robustness check, we further divided our test period into subperiods. In summary, our results during the period Jan 2000 to May 2011 indicate that it would be a good idea for a Kuwaiti investor to use gold in the portfolio. The availability of exchange traded funds (ETF) which invests in Gold bullion makes it easily possible to implement our results in practice.

\section{References}

Baur, D., \& Lucey, B. (2010). Is gold a hedge or a safe haven? An analysis of stocks, bonds and gold. The Financial Review, 45, 217-229, http://dx.doi.org/10.1111/j.1540-6288.2010.00244.x

Beckers, S. \& Soenen, L. (1984).Gold more attractive to non-US than to US investors?. Journal of Business Finance \& Accounting, 11(1), 107-112, http://dx.doi.org/10.1111/j.1468-5957.1984.tb00061.x

Chua, J., Sick, G., \& Woodward, R. (1990). Diversifying with gold stocks. Financial Analysts Journal, 46, 76-79, http://dx.doi.org/10.2469/faj.v46.n4.76

Conover, C., Jensen, G., Johnson, R., \& Mercer, J. (2009). Can precious metals make your portfolio shine?. Journal of investing, Spring, 75-86, http://dx.doi.org/10.3905/JOI.2009.18.1.075

Dickey, D. \& Fuller, W. (1979). Distribution of the Estimators for Autoregressive time series with a Unit Root. Journal of the American Statistical Association, 74(366). 427-431, http://dx.doi.org/10.2307/2286348

Hillier, D., Draper, P., \& Faff, R. (2006). Do precious metals shine? An investment perspective. Financial Analysts Journal. 62(2), 98-106, http://dx.doi.org/10.2469/faj.v62.n2.4085

Jaffe, J. (1989). Gold and Gold stocks as investments for institutional portfolios. Financial Analysts Journal (March/April), 53-59, http://dx.doi.org/10.2469/faj.v45.n2.53

Johansen, S. (1991). Estimation and hypothesis testing of cointegrating vectors in Gaussian vectors autoregressive models. Econometrica, 59, 1551-1580, http://dx.doi.org/10.2307/2938278

Johansen, S. (1995). Likelihood based inference in cointegrated vector autoregressive models. Oxford University Press, Oxford.

Johnson, R., \& Soenen, L. (1997). Gold as an investment asset: Perspectives from different countries. Journal of Investing, 6, 94-99, http://dx.doi.org/10.3905/joi.1997.408427

O’Byrne, M. (2007). Why diversifying into gold may be prudent. Accountancy Ireland, 29(5), 76-77.

Phillips, P., \& Perron, P. (1988). Testing for a unit root in time series regression. Biometrika, 75(2), 335-346, http://dx.doi.org/10.2307/2336182

Ratner, M., \& Klein, S. (2008). The portfolio implications of gold investment. Journal of Investing, Spring, 77-87, http://dx.doi.org/10.3905/joi.2008.701958

World Gold Council Website. [Online] Available: http://www.gold.org/investment (July 12, 2011) 
Table 1. Descriptive Statistics for the period January 2000 to May 2011.

\begin{tabular}{|l|c|c|c|c|c|}
\hline & KSE & GOLD & MSCI & REALESTATE & MM_FUND \\
\hline Mean & 0.010853 & 0.011414 & -0.002127 & 0.004824 & 0.001207 \\
\hline Median & 0.020762 & 0.013990 & 0.005145 & 0.017680 & 0.003300 \\
\hline Maximum & 0.184436 & 0.118828 & 0.095512 & 0.188201 & 0.026400 \\
\hline Minimum & -0.271221 & -0.179769 & -0.168624 & -0.339711 & -0.159800 \\
\hline Std. Dev. & 0.059274 & 0.047276 & 0.044477 & 0.059215 & 0.017243 \\
\hline Skewness & -0.998817 & -0.372758 & -0.801967 & -1.839332 & -7.379993 \\
\hline Kurtosis & 6.664917 & 4.038358 & 3.909545 & 11.45257 & 63.13565 \\
\hline CV & 5.461531 & 4.141931 & -20.910672 & 12.275083 & 14.290543 \\
\hline Jarque-Bera & 99.45150 & 9.327323 & 19.40762 & 485.0859 & 21886.62 \\
\hline Probability & 0.000000 & 0.009432 & 0.000061 & 0.000000 & 0.000000 \\
\hline
\end{tabular}

KSE stands for logarithmic return in Kuwait stock exchange price index, Gold is the monthly change in gold price, MSCI is the return on Morgan Stanley world equity index, RealEstate is the Dow Jones Global real estate equities index, MM_Fund is the money market fund managed by Global investment company in Kuwait.

Table 2. Correlation coefficients between the monthly logarithmic returns of the variables.

Panel (A). Jan 2000 - May 2011

\begin{tabular}{|c|c|c|c|c|c|}
\hline & KSE & GOLD & MSCI & REALESTATE & MM_FUND \\
\hline KSE & 1.000000 & -0.011201 & 0.341527 & 0.414698 & 0.018418 \\
\hline GOLD & -0.011201 & 1.000000 & -0.019679 & 0.121005 & -0.127750 \\
\hline MSCI & 0.341527 & -0.019679 & 1.000000 & 0.709980 & -0.030204 \\
\hline REALESTATE & 0.414698 & 0.121005 & 0.709980 & 1.000000 & -0.002558 \\
\hline MM_FUND & 0.018418 & -0.127750 & -0.030204 & -0.002558 & 1.000000 \\
\hline
\end{tabular}

Panel (B). Period Jan 2007 - May 2011

\begin{tabular}{|c|c|c|c|c|c|}
\hline & KSE & GOLD & MSCI & REALESTATE & MM_FUND \\
\hline GOLD & 0.049977 & 1.000000 & -0.033683 & 0.086911 & -0.153219 \\
\hline MSCI & 0.533404 & -0.033683 & 1.000000 & 0.877406 & -0.045515 \\
\hline REALESTATE & 0.565624 & 0.086911 & 0.877406 & 1.000000 & -0.036415 \\
\hline MM_FUND & -0.033268 & -0.153219 & -0.045515 & -0.036415 & 1.000000 \\
\hline
\end{tabular}

Table 3. Regression results of the return on gold against the return of KSE index

Panel (A)

\begin{tabular}{|c|c|c|c|c|}
\hline \multicolumn{5}{|c|}{$\begin{array}{l}\text { Dependent Variable: GOLD } \\
\text { Method: Least Squares } \\
\text { Sample: 2000M01 2011M05 }\end{array}$} \\
\hline \multicolumn{5}{|c|}{ Newey-West HAC Standard Errors \& Covariance (lag truncation=4) } \\
\hline Variable & Coefficient & Std. Error & t-Statistic & Prob. \\
\hline $\mathrm{C}$ & 0.011511 & 0.003700 & 3.110724 & 0.0023 \\
\hline KSE & -0.008934 & 0.101330 & -0.088167 & 0.9299 \\
\hline R-squared & 0.000125 & & & \\
\hline
\end{tabular}

Panel (B)

\begin{tabular}{|c|c|c|c|c|}
\hline \multicolumn{5}{|c|}{ Dependent Variable: GOLD } \\
\hline \multicolumn{5}{|c|}{ Method: Least Squares } \\
\hline \multicolumn{5}{|c|}{ Sample: 2007M01 2011M05 } \\
\hline \multicolumn{5}{|c|}{ Newey-West HAC Standard Errors \& Covariance (lag truncation=3) } \\
\hline Variable & Coefficient & Std. Error & t-Statistic & Prob. \\
\hline $\mathrm{C}$ & 0.016150 & 0.006086 & 2.653428 & 0.0106 \\
\hline KSE & 0.044086 & 0.205201 & 0.214846 & 0.8307 \\
\hline R-squared & 0.002498 & & & \\
\hline
\end{tabular}


Table 4. Unit root test results

\begin{tabular}{|l|l|l|}
\hline & ADF & PP \\
\hline Gold & -1.347573 & -1.169432 \\
\hline KSE & -1.569674 & -1.359695 \\
\hline
\end{tabular}

The $5 \%$ level test critical value of the Augmented Dickey-Fuller (ADF) test and the Phillips-Perron (PP) test is -3.436 .

Table 5. Johansen Cointegration Rank (Trace) Test Results

\begin{tabular}{|l|c|c|c|}
\hline \multirow{2}{*}{ Test for cointegration between } & \multicolumn{2}{|c|}{ Hypothesized number of cointegrated vectors } & \multirow{2}{*}{ Trace test indicates at the 0.05 level } \\
\cline { 2 - 3 } & $\mathrm{r}=0$ & $\mathrm{r} \leq 1$ & \\
\hline KSE and Gold & 16.68 & 2.12 & No cointegration \\
\hline Critical values at 0.05 & 25.87 & 12.52 & - \\
\hline
\end{tabular}
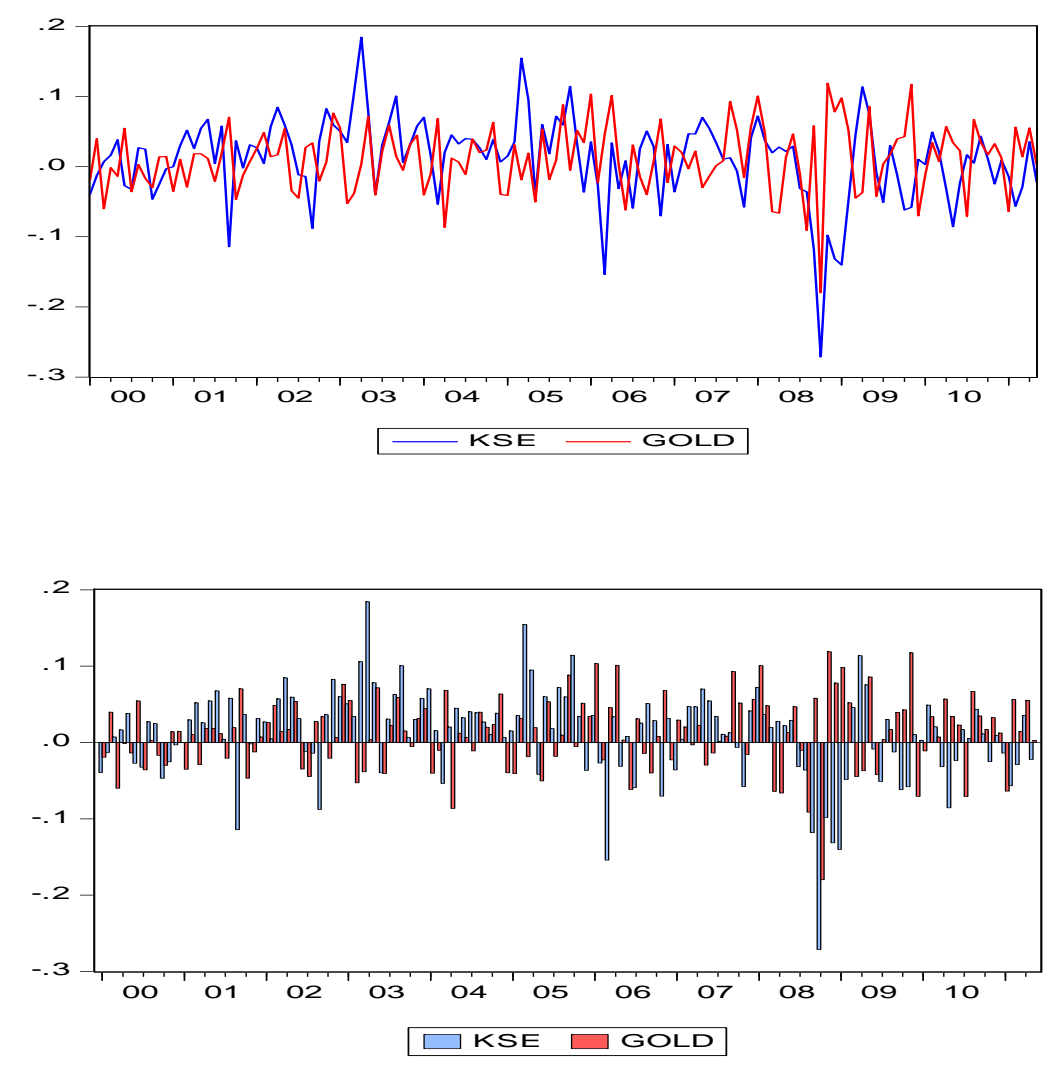

Figure 1. Return pattern of Kuwait stock exchange price index versus Gold prices for the period Jan 2000 - May 2011. 
Panel (A): Period Jan 2000 to May 2011

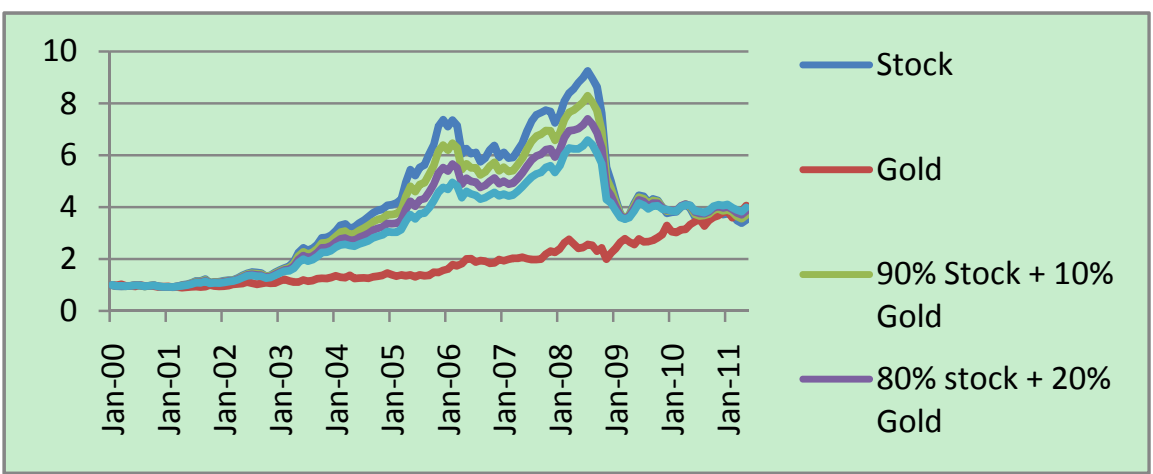

Panel (B). Period Jan 2007 to May 2011

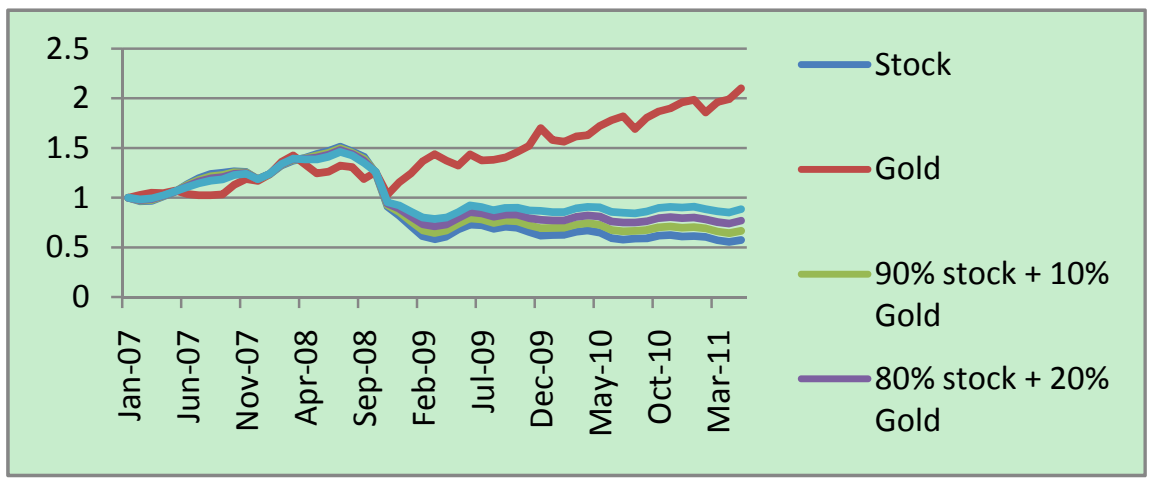

Figure 2. Growth of $1 \mathrm{KD}$ invested in Kuwait equities with and without a Gold exposure 